light on the mechanism underlying fixed-interval behavior only to the extent that credence is given to Pavlov's simple interpretation of delayed conditioning as strong inhibition and weaker excitation during the early part of the delay period which gives way to increasing excitation as the end of the period approaches. Probably the strongest evidence for this interpretation is the demonstration of the "ideal" case of disinhibition; i.e., elevation in responding during the first half of the delay period and depression during the later part of the period (cf. Staddon, 1969). Pavlov's illustrations, however, show that this effect is only one of a variety of possible outcomes, since the "strength" of the disinhibiting stimulus, as well as the strength of inhibition of delay, may vary widely. This account is not wholly satisfying; convincing support would have to begin with some ranking of stimuli according to "inhibitory strength" by a method other than the observation of their effects during the delay period, as was done by Pavlov. The results of their presentation during the delay period (or during the fixed interval) could then be compared with the various outcomes predicted by Pavlov.

\section{REFERENCES}

BLOUGH, D. S. Definition and measurement in generalization research. In D. I Mostofsky (Ed.), Stimulus generalization. Stanford: Stanford University Press, 1965.

FLANAGAN, B., \& WEBB, W. B. Disinhibition and external inhibition in fixed interval operant conditioning Psychonomic Science, 1964, 1, 123-124. HINRICHS, J. V. Disinhibition of delay in fixed-interval instrumental conditioning Psychonomic Science, 1968, 12, 313-314.

KONICK, D. S. \& THOMAS, D. R. Stimulus generalization following fixed interval training. Journal of Experimental Psychology, 1968, 77.689-691.

PAVLOV I. P. Conditioned reflexes. (Translated by G. V. Anrep.) New York Dover, 1927.

SINGH, D. \& WICKENS, D. D. Disinhibition in instrumental conditioning. Journal of Comparative \& Physiological Psychology, 1968, 66. $557-559$.

STADDON, J. E. R. Inhibition and the perant: A review of Sensory inhibition by G. v. Békésy and Mach Bands: $Q$ uantitative studies on the neural networks in the retina by Floyd Ratliff. Journal of the Experimental Analysis of Behavior, $1969,12,481-487$

ZEILER, M. D. Repeated measures of reinforcement schedule effects on gradients of stimulus control. Journal of the Experimental Analysis of Behavior. $1969,12,451-461$

\title{
Partioning of a restricted food source in a territorial iguanid
} (Anolis carolinensis)*

\author{
GEORGE L. COLNAGHI \\ Auditory Research Laboratories, Princeton University, Princeton, N.J. 08540
}

Following a 48-h deprivation period, time samplings of behavior of six pairs of lizards were taken from 9:30 a.m. to 5:40 p.m. each day for 5 days. Each pair of Ss was observed in an area $32 \times 32 \times 16$ in. In all pairs, one animal dominated and supplanted the other throughout the observation area. Food offered during the first day of observation was taken in equal amounts by the dominant and nondominant lizards; food offered on the fifth day was taken almost exclusively by the dominant animals $(90.4 \%)$. This increase is statistically significant $(p<.031)$ and suggests that a territory can function to ensure the holder of that territory all or most of a limited food supply.

A number of authors have suggested that territoriality may serve as a mechanism for assuring an adequate share of the food supply for some minimum number of individuals (e.g.,

\footnotetext{
* From the Department of Psychology. This research was supported by grants from the National Institute of Neurological Diseases and Stroke, Public Health Service, and aided by a contract with the office of Naval Research and by Higgins funds allotted to Princeton University.
}

Altum, 1868; Hediger, 1950; Howard, 1929; Rand, 1967). One prediction which can be derived from this hypothesis is that, under conditions of a food shortage, a territory holder will take all or most of the food available within its territory. This study is a test of this prediction in a territorial Iguanid, Anolis carolinensis.

\section{METHOD}

Eighteen adult male Anolis carolinensis, obtained commercially, were maintained, nine each, in two glass terraniums, $18 \times 10 \times 9.5 \mathrm{in}$. The tanks were placed opposite a window with an eastern exposure. Normal daylight was augmented from 5 a.m. to 9 p.m. by a $40-\mathrm{W}$ incandescent bulb, placed 4 in. above each tank top. The tanks were heated from below and maintained at $28^{\circ} \mathrm{C}$. A petri dish of water and an abundance of $1 / 4$ - to $1 / 2$-in. crickets were continuously available in the tanks.

When the lizards were first placed in the tanks, fighting was virtually continuous. Aggressive displays such as head bobs, extensions of dewlap, and push-up displays (Noble \& Bradley, 1933) were frequently initiated by any of several lizards. Often as many as four animals would be involved in a single fight. Within 2 days, the level of fighting was greatly reduced, and the majority of aggressive actions were initiated by one lizard. Those initiated by other animals were rarely directed at this "dominant" lizard. The dominant individual moved freely throughout the tank, chasing any other animals in his path. In contrast, the nondominant lizards avoided the dominant and either flattened themselves against the ground or fled at his approach.

On June 1 , the dominant lizard was removed from each tank and placed in the observation area (OA). Upon their removal, fighting again erupted in the home tanks, eventuating in the establishment of two new dominant animals. These two served, in turn, for the following week's observations. A new pair of $S s$ was selected in this manner for each set of observations. The Ss were placed in the OA on a Saturday morning and were observed from the following Monday through Friday for $10 \mathrm{~min}$ of each hour, 9:30 a.m. $-5: 40$ p.m. A single mealworm (Tenebrio larve) was placed at the center of the area at 11:30, $2: 30$, and $5: 30$. Water was continuously available. In all, six pairs were observed, but data on the first pair is incomplete for the first 2 days of observation.

The observation area consisted of a 32-in.-square area, enclosed by a 16-in.-high unpainted plywood wall, and covered with a removable wire mesh top. The floor and walls were marked off into 8-in. squares with $1 / 4$-in. black tape. Light and heat were provided from 5:00 a.m. to 9:00 p.m. by a $250-W$ incandescent bulb, hung 22 in. above the center of the area. The temperature directly under the lamp was thereby maintained at $26^{\circ}-28^{\circ} \mathrm{C}$ during the day, dropping to room temperature (approximately $24^{\circ} \mathrm{C}$ ) at night. Two plywood platforms, $1 \times 1 \times 1 \frac{1}{2}$ in., were placed at the center of opposite walls. 
During each observation period the $E$ recorded the number of squares entered and the number and type of aggressive actions initiated by each $\mathrm{S}$. When the mealworms were offered the E also noted which animal took the worm and the latency of that response.

RESULTS AND DISCUSSION

The level of aggressive activity observed in the 259 observation periods was decidedly low. In all, 108 occurrences were recorded, and of these, 78 involved only charging (i.e., rushing directly at and thereby driving off the other $S$ ). Over $83 \%$ of all aggressive activity occurred in the first three pairs of Ss. Though the incidence of aggressive acts was often low, the dominant and nondominant animals could be distinguished. The nondominant animal typically moved about in short dashes, flattening itself against the ground when it stopped. When approached by the dominant animal, the nondominant would either flatten itself out, remaining motionless, or run off, often dashing headlong into the walls of the area. These behaviors were rarely observed in the dominant animal, which was able to supplant, most often by its mere approach, the nondominant everywhere within the area.

Of the 88 worms offered during the study, the dominant animals took 62 (70.4\%). In all but Pair 2, the dominant took a greater percentage of the food offered on Day 5 than on Day 1. A sign test of this increase ( $90.4 \%$ on Day 5 vs $50 \%$ on Day 1) was statistically significant $(\mathrm{N}=5$, $X=0, p<.031)$. This increase was symptomatic of a general day-to-day increase in food taking (Fig. 1). The reversal of this pattern on Day 4 was not the result of any one deviant pair, and the source of this change is not apparent.

The number of squares entered per observation period was taken as a measure of activity. When averaged across all pairs, there were no statistically significant differences in activity between Day 1 and Day 5 for either the dominant or nondominant animals, or between the activity of the dominant and nondominant on any one of the days. If the average daily activity of each pair is plotted separately, however, they appear to fall into two groups-Pairs 1-3 and Pairs 4-6 (Fig. 2). Whether this apparent difference in the activity levels of the nondominant animals is representative of a real difference in mode of adjustment is a question which cannot be answered with this limited data. The $S$ selection procedures employed would, at any rate, ensure that the most active and

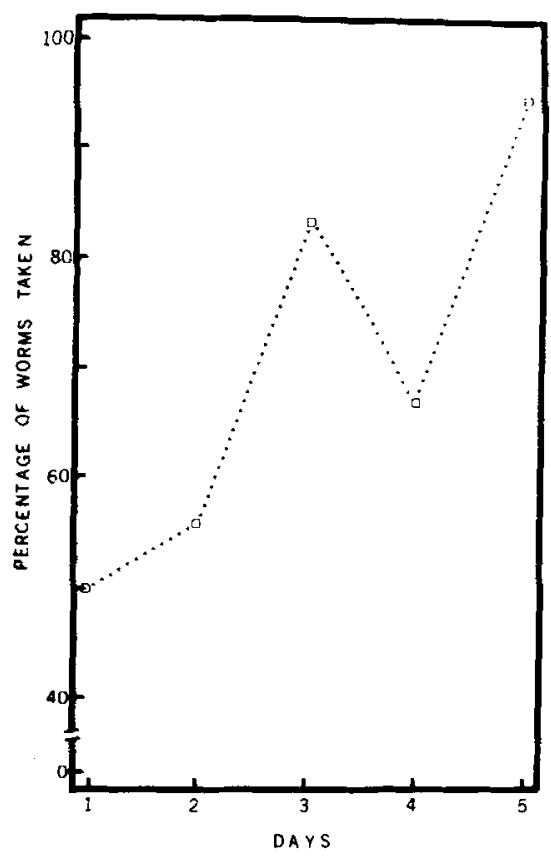

Fig. 1. Percentage of worms taken by all dominant animals on Days 1-5.

aggressive lizards would be chosen first. What is reasonably clear is that, in accordance with the prediction, the dominant animal does supplant the nondominant with respect to the critical resource.
A logical extension of this study would be a test of a second and more interesting implication of the resource partitioning hypothesis, i.e., that territory size should, within limits, be proportional to the availability of critical resources. Such a test might be accomplished by enlarging the observation area and providing an unlimited supply of food and water at opposite ends of this area. If the area were large enough, two territories could develop around each food supply. Once the limits of these territories were recognized, the two food supplies could be removed and a single, much reduced supply substituted at the boundary between the territories. Increased fighting resulting in new boundary lines and differential food taking would be predicted.

ALTUM, B, Der Vogel und sein Leben Munster: Rieman, 1868

HEDIGER, H. Wild animals in captivity. London: Butterworths, 1950.

HOWARD, H. E. An introduction to the study of bird behavior. Cambridge: Cambridge University Press, 1929.

NOBLE, G. K., \& BRADLEY, H. T. The mating behavior of lizards: Its bearing on the theory of sexual selection. Annals of the New York Academy of Science, 1933, 35, 25-100.

RAND, A. S. The adaptive significance of territoriality in Iguanid lizards. In $W$. W. Milstead (Ed.), Lizard ecology: $A$ symposium. Columbia, Missouri: University of Missouri Press, 1967.

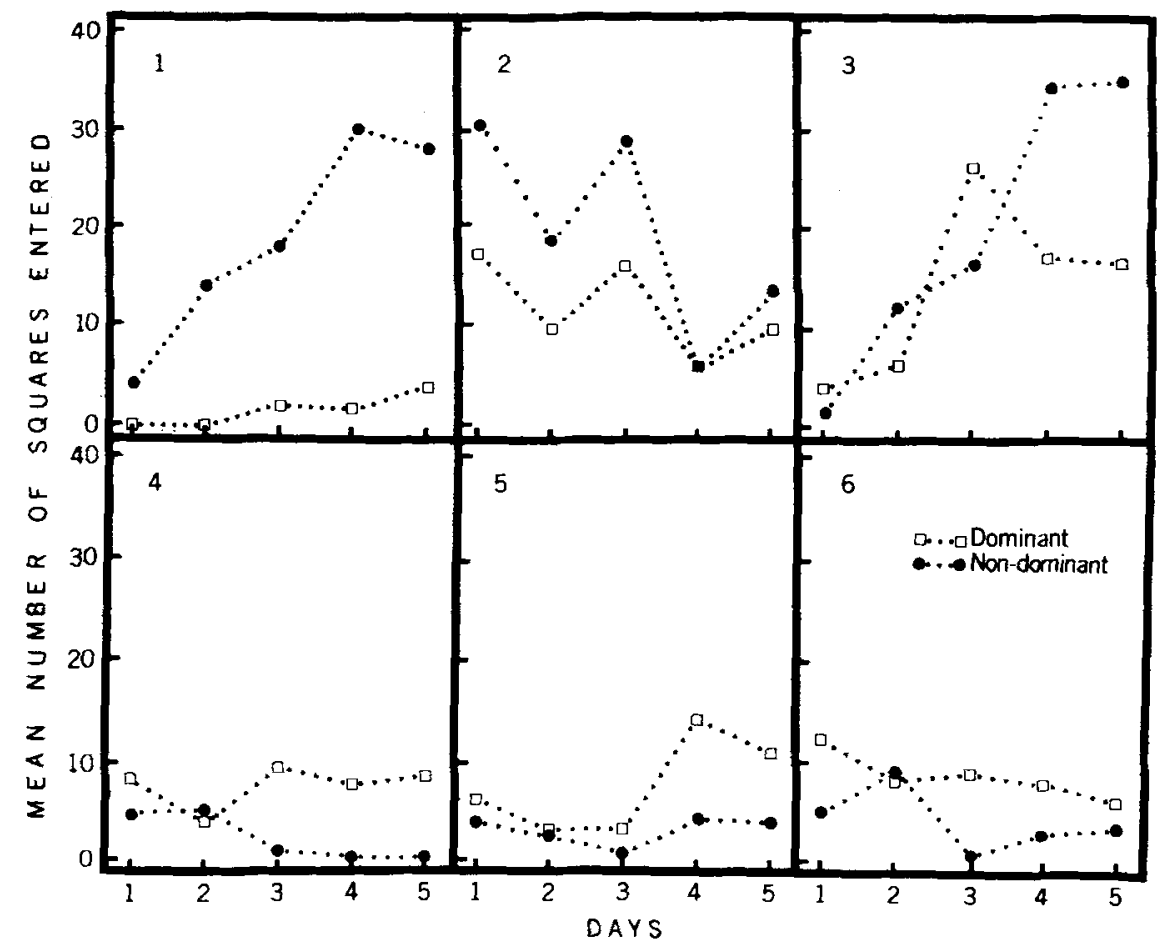

Fig. 2. Mean number of squares entered over the 5 days of observation of each pair of Ss. 